- Growth hormone rose considerably during some procedures. Apparently "stressful" procedures included herniotomy and adenoidectomy, whereas endoscopy or treatment of hydrocephalus generally produced no rise. No reactive rise in growth hormone was detected when children became hypoglycaemic, except in cases 7 and 10, but measurements were limited (table III).

Insulin was measured in only a few patients. The very high level in case 10 is hard to explain, but presumably accounted for the hypoglycaemia. A detectable level during hypoglycaemia in case 51 implied impairment of the ability to "switch off" insulin.

Preoperative fasting ranged from three and a quarter hours to 24 hours, all except one being more than four hours. Twenty-eight $\left(49^{\circ}{ }_{0}\right)$ patients fasted for more than eight hours, and nine $(15.8 \%)$ for more than 12 hours.

Postoperative feeds-Most children were given fluids, usually orange squash or $5^{\circ}$ dextrose but occasionally milk, within four to six hours of returning to the ward. None of the six hypoglycaemic children had drunk any fluids when they were hypoglycaemic, although one was having intravenous dextrose-saline $\left(4 \cdot 3^{\circ}\right.$ o dextrose). Case 7 , who had a borderline plasma glucose concentration and a considerable rise in growth hormone at six hours, had received $200 \mathrm{ml}$ orange squash, starting two hours after the operation (table III).

Anaesthetics-Nitrous oxide and oxygen, halothane, and occasionally cyclopropane for induction and maintenance were given in most cases.

\section{Discussion}

Blood glucose may fall during a preoperative fast and in some small children reaches hypoglycaemic levels at induction. Features are rare, but may be masked by drugs used for premedication.

During surgery, stress hormones tend to increase, producing a rise in plasma glucose, the degree of which is a function of the "severity" of the surgery. "This phenomenon is said to be absent or less marked in children than in adults, ${ }^{2}$ though it was present in some of these patients. The effect may be mitigated by administration of anaesthetics, to a degree which depends upon the depth of anaesthesia. Anaesthetic agents alone may raise plasma glucose, especially in animals, but there is little evidence that this occurs in man.

In the immediate postoperative period $10 \%$ of the children in this series became hypoglycaemic. This was probably owing to a combination of fasting, often for as long as 24 hours, and rebound after the hyperglycaemia induced by surgery. One child seemed unable to "switch off" insulin, and this may be a further mechanism.

None of the children had symptoms, and it would be difficult to establish whether isolated low levels of glucose are important. Small children, however, are more sensitive to hypoglycaemia than older children or adults, and few paediatricians would be sanguine about levels of this order persisting for any length of time. One of us has found a 13-month-old child in a coma with undetectable blood glucose eight hours after a laparotomy; the child subsequently died without regaining consciousness.

Some small children may develop low plasma glucose levels in the postoperative period. Low birthweight or underweight children, very young babies, and children with liver, endocrine, or central nervous system disease might be expected to be particularly at risk, although hypoglycaemia may occur in the absence of any of these factors. The findings confirm and extend the dangers of a long preoperative fast, and indicate that it is wise to introduce calories as soon as practicable after the operation, preferably with a milk feed. Intravenous fluids do not always prevent hypoglycaemia.

We are grateful to $\mathrm{Mr} \mathrm{J} \mathrm{O} \mathrm{N}$ Lawson and Dr P H Sonksen for advice and encouragement, to the ward nurses and anaesthetists at St Thomas's and the Westminster Children's Hospitals for taking blood samples and filling in the protocol, and to Ms K H Quine, BSc and the department of medicine for performing the assays.

The work was partly supported by a grant from the British Diabetic Association.

\section{References}

1 J J Morrice, et al, Archives of Disease in Childhood, 1974, 49, 898.

2 B G Watson, British fournal of Anaesthesia, 1972, 44, 712.

3 D K M Thomas, British fournal of Anaesthesia, 1974, 46, 66.

${ }^{4}$ British Medical fournal, 1974, 3, 213.

5 P H Sonksen, et al, Clinical Science and Molecular Medicine, 1973, 45, 633.

6 Cornblath, M, and Schwartz, R, Disorders of Carbohydrate Metabolism in Infancy, p 193. Philadelphia and London, Saunders, 1966.

${ }^{7} \mathrm{R}$ S Clarke, British fournal of Anaesthesia, 1970, 42, 45.

\title{
Completeness of statutory notification for acute bacterial meningitis
}

\author{
M J GOLDACRE, D L MILLER
}

British Medical Fournal, 1976, 2, 501-503

\section{Summary}

Several different sources of data, including statutory notifications, were used to identify cases of acute bacterial meningitis in childhood in a defined population. Only half the cases of meningococcal meningitis and less

\footnotetext{
University Department of Social and Community Medicine, Oxford OX1 3QN

M J GOLDACRE, BM, MSC, lecturer

Middlesex Hospital Medical School Department of Community Medicine, London NW10 7NS

D L MILLER, MRCP, FFCM, professor
}

\begin{abstract}
than one quarter of other types of bacterial meningitis had been notified. Notified cases differed from the remainder with respect to causative organism, age, outcome, and type of hospital of admission. Thus notifications are an unreliable measure of incidence for this disease, and studies of infectious disease based on notified cases alone should be interpreted with considerable reserve. It is suggested that infectious-disease surveillance should be both clinical and microbiological and that data from different sources need to be co-ordinated. The reason for reporting each disease (or organism) should be specified and reviewed periodically.
\end{abstract}

\section{Introduction}

Nationwide statutory notification of certain infectious diseases started in 1922, although it was obligatory earlier in some local 
authority areas. Tabulations of notifications are published weekly, quarterly, and annually by the Registrar General. Despite the cumulative effort invested in notification, record keeping, and publication over several decades there are surprisingly few studies of the accuracy and completeness of notification statistics. In 1949 Stocks showed that the completeness of notification seemed to vary considerably according to the illness. ${ }^{1}$ A recent study suggests substantial underreporting of infectious diseases by general practitioners. ${ }^{2}$

In an epidemiological study of acute bacterial meningitis in childhood in the North-west Metropolitan Region, several different data sources, including statutory notifications, were used to identify cases. This enabled us to assess how complete and how representative notified cases were, compared with all cases identified. We describe the results of this comparison and comment on the role of statutory notification in the surveillance of infectious disease.

\section{Patients and methods}

We tried to identify every case of acute bacterial meningitis in children under 10 years of age occurring from 1969 to 1973 in the North-west Metropolitan Region (regional hospital board boundaries: about 630000 children). Cases were sought from hospital discharge data (hospital activity analysis and individual hospital diagnostic indexes), microbiology laboratory records, and death certificates. In addition, every medical officer of health whose local authority area was wholly or partly within the region gave permission for the original statutory notification forms received in his department to be studied. Every authority had records covering all five years.

Case notes for each patient identified from any of the above sources were obtained at the hospital concerned and relevant information was abstracted from them. The diagnostic criteria for inclusion in the study have been described in detail. ${ }^{3}$ In brief, children with acute pyogenic meningitis which was either bacteriologically confirmed or treated clinically as bacterial in aetiology were included. This report covers only those patients who lived in the region and who were admitted to a hospital in the region or who died outside hospital. We excluded $(a)$ patients for whom bacterial meningitis was notified but where the above criteria for the diagnosis were not met, $(b)$ patients with underlying neuroanatomical lesions, and $(c)$ patients with meningococcal septicaemia but without evidence of meningitis (meningococcal septicaemia is not notifiable). We thus excluded 16 patients with meningococcal septicaemia and an additional 20 patients in the general study ${ }^{3}$ who were admitted to hospitals within the region but who lived outside it.

Accordingly, the proportion of cases notified has been calculated by taking as the numerator the number of cases of acute bacterial meningitis confirmed by review of case notes for which a notification was received, and as the denominator the total number of cases in the same population identified and verified from all data sources.

\section{Results}

Notifications were found for half the cases of meningococcal meningitis, $16 \%$ of haemophilus, $17 \%$ of pneumococcal, $11 \%$ of other types of bacterial meningitis, and $8 \%$ of cases of sterile pyogenic meningitis (table I). Notifications were found for $88 \%$ of cases admitted to infectious disease hospitals (and for all their cases of meningococcal meningitis), $26 \%$ of cases admitted to teaching hospitals, and $19 \%$ of cases admitted to general hospitals (table II).

TABle I-Cases by organism. Percentages are given in parentheses

\begin{tabular}{|c|c|c|c|}
\hline Organism & $\begin{array}{l}\text { No of notified } \\
\text { cases }\end{array}$ & $\begin{array}{l}\text { Total No of } \\
\text { cases }\end{array}$ & $\begin{array}{c}\text { Percentage of } \\
\text { notified cases to }\end{array}$ \\
\hline $\begin{array}{l}\text { Meningococcus } \\
\text { Haemophilus influenzae } \\
\text { Pneumococcus } \\
\text { Other named organisms } \\
\text { Organisms unknown ... }\end{array}$ & $\begin{array}{rr}119 & (66 \cdot 1) \\
31 & (17 \cdot 2) \\
11 & (6 \cdot 1) \\
7 & (3 \cdot 9) \\
12 & (6 \cdot 7)\end{array}$ & $\begin{array}{rr}240 & (34 \cdot 2) \\
189 & (26 \cdot 9) \\
66 & (9 \cdot 4) \\
63 & (9 \cdot 0) \\
144 & (20 \cdot 5)\end{array}$ & $\begin{array}{r}49 \cdot 6 \\
16 \cdot 4 \\
16 \cdot 7 \\
11 \cdot 1 \\
8 \cdot 3\end{array}$ \\
\hline Total & $180(100 \cdot 0)$ & $702(100 \cdot 0)$ & $25 \cdot 6$ \\
\hline
\end{tabular}

Comparison between notified and unnotified cases, $\chi^{2}=113,4 \mathrm{DF}, \mathrm{P}<0.001$.
TABLE II-Cases by type of hospital. Percentages are given in parentheses

\begin{tabular}{|c|c|c|c|}
\hline Type of hospital & $\begin{array}{l}\text { No of notified } \\
\text { cases }\end{array}$ & $\begin{array}{l}\text { Total No of } \\
\text { cases }\end{array}$ & $\begin{array}{l}\text { Percentage of } \\
\text { notified cases to }\end{array}$ \\
\hline General hospitals & $98 \quad(54 \cdot 4)$ & $509 \quad(72 \cdot 5)$ & $19 \cdot 3$ \\
\hline $\begin{array}{l}\text { hospitals } \quad . . \\
\text { Infectious dise }\end{array}$ & $29(16 \cdot 1)$ & $112(16 \cdot 0)$ & $25 \cdot 9$ \\
\hline $\begin{array}{l}\text { nfectous disease } \\
\text { hospitals } \\
\text { Maternity hospitals } \\
\text { Died outside hospital }\end{array} \quad$. & $\begin{array}{rr}52 & (29.9) \\
1 & (0.6)\end{array}$ & $\begin{array}{ll}59 & (8 \cdot 4) \\
12 & (1 \cdot 7) \\
10 & (1 \cdot 4)\end{array}$ & $\begin{array}{r}88 \cdot 1 \\
8 \cdot 3\end{array}$ \\
\hline Total & $180(100 \cdot 0)$ & $702(100 \cdot 0)$ & $25 \cdot 6$ \\
\hline
\end{tabular}

Comparison between notified and unnotified cases, general, teaching, and infectious disease hospitals only, $x^{2}=129,2 \mathrm{DF}, P<0 \cdot 001$

TABle III-Cases by age group. Percentages are given in parentheses

\begin{tabular}{|c|c|c|c|c|}
\hline \multicolumn{2}{|l|}{ Age group } & $\begin{array}{l}\text { No of notified } \\
\text { cases }\end{array}$ & $\begin{array}{l}\text { Total No of } \\
\text { cases }\end{array}$ & \multirow{2}{*}{$\begin{array}{c}\begin{array}{c}\text { Percentage of } \\
\text { notified cases to } \\
\text { all cases }\end{array} \\
8.3 \\
23.3 \\
28.9 \\
32 \cdot 8\end{array}$} \\
\hline $\begin{array}{l}\text { Under } 4 \text { weeks. } \\
4-51 \text { weeks } \\
\text { 1-4 years } \\
5-9 \text { years }\end{array}$ & $\begin{array}{l}\because \\
\because \\
\therefore\end{array}$ & $\begin{array}{rr}6 & (3 \cdot 3) \\
52 & (28 \cdot 9) \\
84 & (46 \cdot 7) \\
38 & (21 \cdot 1)\end{array}$ & $\begin{aligned} 72 & (10 \cdot 2) \\
223 & (31 \cdot 8) \\
291 & (41 \cdot 5) \\
116 & (16 \cdot 5)\end{aligned}$ & \\
\hline Total & & $180(100 \cdot 0)$ & $702(100 \cdot 0)$ & $25 \cdot 6$ \\
\hline
\end{tabular}

Comparison between notified and unnotified cases, $\chi^{2}=16 \cdot 6,3 \mathrm{DF}, \mathrm{P}<0.01$.

TABLE IV-Cases by outcome. Percentages are given in parentheses

\begin{tabular}{|c|c|c|c|c|c|}
\hline \multicolumn{3}{|c|}{ Outcome } & $\begin{array}{l}\text { No of notified } \\
\text { cases }\end{array}$ & $\begin{array}{c}\text { Total No of } \\
\text { cases }\end{array}$ & \multirow{2}{*}{$\begin{array}{c}\begin{array}{c}\text { Percentage of } \\
\text { notified cases to } \\
\text { all cases }\end{array} \\
13.9 \\
27 \cdot 1\end{array}$} \\
\hline $\begin{array}{l}\text { Deaths ... } \\
\text { Survivors }\end{array}$ & $\therefore$ & 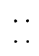 & $\begin{array}{rr}11 & (6 \cdot 1) \\
169 & (93 \cdot 9)\end{array}$ & $\begin{array}{rr}79 & (11 \cdot 3) \\
623 & (88.7)\end{array}$ & \\
\hline \multicolumn{3}{|c|}{ Total } & $180(100 \cdot 0)$ & $702(100 \cdot 0)$ & $25 \cdot 6$ \\
\hline
\end{tabular}

Comparison between notified and unnotified cases, $\chi^{2}$ with Yates's correction $=5 \cdot 7$, $1 \mathrm{DF}, \mathrm{P}<0.02$.

No case in which death occurred outside hospital was notified Meningitis was notified much less often in the neonatal age group than at later ages (table III). Fatalities were notified less often than survivors (table IV).

\section{Discussion}

In 1949 Stocks considered that "it can be assumed that notification of meningococcal infection, when diagnosed, is almost complete."1 A more recent comparison of notification statistics with hospital discharge statistics for this illness suggests that only about half of all cases are now notified, ${ }^{4}$ and our study confirms this. Other types of acute bacterial meningitis were notified much less often.

It is no surprise that notification is incomplete. This probably reflects, in part, doctors' views on the value of notification, which may vary for different infections; in part, their awareness of which diseases are notifiable; and whether they remember to notify. The extent to which incomplete notification matters depends on how the notifications are used. Their unique use is to enable swift local action to be taken to control the spread of infection. The more often notification is omitted, the less effectively can this function be discharged when necessary. The importance of notification for this purpose depends on the nature of the infection-for example, it is clear in the case of poliomyelitis or salmonellosis but less so for measles cr pertussis. If only half the cases of a serious illness such as meningococcal meningitis are notified other serious infections are probably not reported, and for minor illnesses the deficit may be much greater.

The second use of notification is to monitor trends in disease incidence, locally and nationally, in order to alert doctors to the presence of particular infections and to assess the need for or 
effectiveness of preventive measures, such as immunisation. Lambert showed that trends in the notifications of meningococcal infection corresponded well with those in hospital admission and in mortality data. ${ }^{*}$ Our data were insufficient to assess this correlation accurately. Nevertheless, they expose clearly the fallacy of concluding from the annual number of deaths from meningococcal infection and the number of notifications that "one patient in four still dies" from this illness.

The third important use of notifications is to study the epidemiology, spread, and relative importance of different infections. The results of such studies will be misleading if notified cases are unrepresentative. In this study, $66 \%$ of notified cases of bacterial meningitis were meningococcal compared with $34^{\circ}$ o of all cases identified (table I); $30 \%$ of notified cases had been admitted to infectious disease hospitals compared with only $8^{\circ}$ " of all cases (table II); $3^{\circ}{ }_{0}$ of notified cases were in neonates compared with $10^{\circ}$ of all cases (table III); and the case fatality rate was only $6^{\circ}{ }_{0}$ for notified cases compared with $11^{\circ}$ o for all cases (table IV). There were no notifications for children who died outside hospital. These findings suggest the possibility of serious bias in studies based solely on cases identified from notifications.

This situation, in which notifications of an important and dangerous group of infections such as bacterial meningitis are seriously deficient, is clearly unsatisfactory. It has been suggested that reports from microbiological laboratories would provide a more reliable source of surveillance data than clinical notification. ${ }^{6}$ But microbiological confirmation is unusual in some illnesses (such as measles) and variable in others (such as meningitis) and should not be the sole criterion for reporting the diagnosis. Responsibility for statutory notification of clinical disease probably rests most appropriately with the clinicians. ${ }^{7}$ Laboratory reports, however, may often provide com- plementary data by identifying unnotified cases and carriers and add invaluable information by monitoring the types and properties of organisms. The most appropriate source of surveillance data varies with the nature of the infection, the purpose to be achieved by reporting it, and the urgency with which information is required. The requirements for each disease (or organism) should be defined and reviewed periodically.

The essential lesson of our findings is that infectious-disease surveillance should not be dependent on one source of information alone. Data from all available sources-especially statutory notifications and microbiology laboratories-need to be exchanged and integrated routinely at both local and national level to obtain a complete and accurate description of the facts.

We thank the clinical consultants, medical officers of health, directors of diagnostic microbiology laboratories, medical records officers, and their staff throughout the North-west Metropolitan Region for their kind co-operation, and Mr R A Dewar for help with the analysis of the data. This work was done as part of the MSc, social medicine, course at the London School of Hygiene and Tropical Medicine (MJG).

\author{
References \\ ${ }^{1}$ Stocks, P, Studies on Medical and Population Subjects, No 2. London, \\ HMSO, 1949. \\ 2 Haward, R A, Lancet, 1973, 1, 873. \\ 3 Goldacre, M J, Lancet, 1976, 1, 28. \\ ${ }^{4}$ Lambert, P M, Community Medicine, 1973, 1, 279. \\ ${ }^{5}$ Department of Health and Social Security, On the State of the Public \\ Health 1965. London, HMSO, 1966. \\ ${ }^{6}$ Grist, N R, Lancet, 1974, 1, 30. \\ ' McKendrick, G D W, Lancet, 1974, 1, 91.
}

\author{
Summary \\ Nulliparous women have a greater risk of developing \\ breast cancer than women who have borne children, \\ but so far no functional differences in breast tissue have \\ been reported between parous women and nulliparae. \\ Macroscopically and histologically normal breast tissue \\ was obtained from 74 women of reproductive age during \\ biopsy of benign breast lesions and was examined for the \\ MRC Unit of Reproductive Biology, Edinburgh EH1 2 QW \\ J O DRIFE, BSC, MB, MRC research fellow \\ University Department of Therapeutics, Royal Infirmary, Edinburgh \\ D B L MCCLELLAND, BSC, MRCP, lecturer \\ ANNE PRYDE, AIMLS, technician \\ Department of Clinical Surgery, University of Edinburgh \\ $M$ MAUREEN ROBERTS, BSC, MD, lecturer \\ Department of Pathology, University of Edinburgh \\ I I SMITH, MB, PHD, senior lecturer
}

presence of plasma cells by immunofluorescence. Immunoglobulin synthesis was detected by an in-vitro culture technique.

Synthesis of IgA was detected in $81 \%$ of specimens, of IgG in $45 \%$, and of IgM in $3 \%$. IgA synthesis was much more intense than IgG or IgM synthesis. Plasma cells containing IgA were seen in $71 \%$ of the specimens examined, and $88 \%$ of specimens had deposits of $\operatorname{IgA}$ in the ductules. The findings were not significantly influenced by the nature of the condition necessitating biopsy or by oral contraception. Nulliparous women showed no cyclical changes, but among parous women IgA synthesis was more intense during the luteal phase of the menstrual cycle. This suggests that after the first pregnancy the breast is more sensitive to progesterone.

\section{Introduction}

The term "resting breast" is often applied to the human mammary gland that is not secreting milk, implying that the gland is metabolically inactive. Small amounts of secretion can be aspirated from at least $75 \%$ of non-lactating breasts, ${ }^{1}$ however, 